\title{
Hubungan Kepemimpinan Spiritual dan Budaya Organisasi dengan Kepuasan Kerja Karyawan PT Sinar Sakti Kimia
}

\author{
Sheena Junita \\ Program Studi Manajemen, Universitas Kristen Petra \\ J1. Siwalankerto No.121-131, Surabaya 60236 \\ E-Mail: shenna_junita@yahoo.com \\ Eddy M. Sutanto \\ Program Studi Manajemen, Universitas Kristen Petra \\ Jl. Siwalankerto No.121-131, Surabaya 60236 \\ E-Mail: eddy_m_sutanto@yahoo.com
}

\begin{abstract}
This research was conducted to find out the job satisfaction of employees in relation to spiritual leadership and organizational culture. The aim is to contribute to the academic and business research, so knowing how to maximize employee job satisfaction. The analysis techniques used in this research is with the method of chi square and pearson correlation, both methods are used to determine the relationship between research variables occur. The results showed that job satisfaction has a positive relationship is indicated by the value of the coefficient contingency 0,520 for variables of spiritual leadership and job satisfaction and the value of the coefficient contingency 0,550 for variables of organizational culture and job satisfaction. Variable spiritual leadership and organizational culture each have a strong relationship with job satisfaction is evident from the $r$ value of 0.524 .
\end{abstract}

Keywords: job satisfaction, spiritual leadership, organizational culture.

\begin{abstract}
ABSTRAK
Penelitian ini dilakukan untuk mengetahui kepuasan kerja karyawan dalam hubungannya dengan kepemimpinan spiritual dan budaya organisasi. Tujuannya adalah untuk memberikan kontribusi bagi penelitian akademik maupun bisnis, sehingga mengetahui cara untuk memaksimalkan kepuasan kerja karyawan. Teknik analisis yang digunakan dalam penelitian ini adalah dengan metode chi square dan korelasi pearson, kedua metode tersebut digunakan untuk mengetahui hubungan yang terjadi antar variabel penelitian. Hasil penelitian menunjukkan bahwa kepuasan kerja memiliki hubungan positif seperti yang ditunjukkan oleh nilai koefisien kontingensi sebesar 0,520 untuk variabel kepemimpinan spiritual dan kepuasan kerja dan nilai koefisien kontingensi sebesar 0,550 untuk variabel budaya organisasi dan kepuasan kerja. Variabel kepemimpinan spiritual dan budaya organisasi masing-masing memiliki hubungan kuat dengan kepuasan kerja yang ditunjukkan dari nilai $r$ sebesar 0,524 .
\end{abstract}

Kata Kunci: kepuasan kerja, kepemimpinan spiritual, budaya organisasi. 


\section{PENDAHULUAN}

Menurut survei yang dilakukan oleh Linkedin, dalam Talent Trends 2014, menunjukkan bahwa sebanyak $84 \%$ profesional di Indonesia mengatakan bahwa mereka puas dengan pekerjaan mereka saat ini. Angka ini lebih tinggi dari rata-rata dunia (72\%), dan negara-negara seperti Swedia (83\%), Norwegia (81\%), Hongkong (67\%), Italia (67\%), Jepang (65\%), serta Turki (63\%) (Srinivasan et al., 2014). Melihat kondisi tersebut perusahaan-perusahaan di Indonesia dalam meningkatkan kepuasan kerja sangat dipengaruhi oleh kepemimpinan dan budaya organisasi. Dalam Penelitian yang dilakukan oleh Aydin dan Ceylan (2009), menunjukkan bahwa kepuasan kerja karyawan memiliki korelasi positif yang signifikan dengan budaya organisasi dan kepemimpinan spiritual.

Banyak bentuk kepemimpinan yang berhubungan dengan kepuasan kerja karyawan, salah satunya adalah kepemimpinan spiritual. Model kepemimpinan spiritual didukung karena mulai banyaknya ahli manajemen dan kepemimpinan modern yang menyadari pentingnya nilai-nilai spiritual untuk menyertai kegiatan bisnis, antara lain mencakup kejujuran, semangat atau optimisme, kebijaksanaan, serta keberanian dalam mengambil keputusan dan bertindak (Muslich, 2014). Hasil dari sebuah survei yang dilakukan oleh International Institute for Spiritual Leadership (IISL) juga menunjukkan bahwa hasil survei mendukung kepemimpinan spiritual dapat membawa pengaruh positif yang signifikan pada kehidupan karyawan dan kepuasan kerja (Fry dan Nisiewicz, 2013). Penelitian lain yang dilakukan oleh Abdizadeh et al. (2014) juga menunjukkan bahwa kepemimpinan spiritual memiliki hubungan positif pada kepuasan kerja karyawan. Menurut Fry dan Nisiewicz (2013) kepemimpinan spiritual merupakan penggabungan nilai-nilai, sikap dan perilaku yang diperlukan untuk memotivasi diri sendiri dan orang lain sedemikian rupa secara instrinsik sehingga mereka memiliki rasa pertahanan spiritual melalui panggilan tugas dan keanggotaan, dalam tulisan tersebut, Fry membangun teori kepemimpinan spiritual melalui kekuatan motivasi instrinsik yang bersumber dari nilai-nilai spiritual yang ada dalam diri manusia. Fry juga masih membedakan antara spiritualitas dengan agama. Menurutnya, spiritualitas lebih luas dibandingkan dengan agama, namun agama dengan spiritualitas dapat dijembatani melalui cinta yang altruistik

Kepemimpinan spiritual yang diterapkan dalam sebuah perusahaan tentunya juga memiliki suatu tugas agar tercapainya tujuan perusahaan secara efektif. Sesuai dengan yang diungkapkan oleh Fry (2003) bahwa kepemimpinan spiritual juga bertugas membangun suatu budaya organisasi berdasarkan cinta alturistik di mana pemimpin dan pengikut sungguh saling perhatian, peduli dan menghargai satu sama lain, sehingga menghasilkan rasa keanggotaan, merasa dipahami dan dihargai.

Budaya organisasi dapat menjadi sebuah instrumen keunggulan yang kompetitif dan utama, bila dapat mendukung strategi dari sebuah organisasi dan mampu menjawab serta mengatasi tantangan lingkungan secara tepat dan cepat (Soedjono, 2005). Menurut Lunnenburg (2011) sebuah perusahaan dinilai sangat perlu memiliki budaya organisasi yang dapat menunjang kinerja baik karyawan dan perusahaan, karena budaya organisasi dapat memiliki pengaruh yang signifikan terhadap sikap dan perilaku anggota organisasi. Sesuai yang dinyatakan oleh Bhatti dan Qureshi (2007) bahwa organisasi yang efektif harus memiliki budaya yang dapat mendorong kepuasan karyawannya. Penelitian yang dilakukan oleh Satyawati dan Suartana (2014), juga menunjukkan bahwa terdapat pengaruh positif antara budaya organisasi dengan kepuasan kerja.

Kepuasan kerja karyawan sudah lama menjadi sorotan utama para pelaku bisnis di Indonesia, sehingga pada penelitian ini mencoba mengangkat fenomena yang terjadi di perusahaan PT Sinar Sakti Kimia yang merupakan perusahaan manufaktur penghasil bahan kimia. Perusahaan PT Sinar Sakti Kimia menerapkan kepemimpinan spiritual dalam pengelolaan perusahaannya, hal tersebut terlihat dari visi, dan kegiatan yang ada dalam perusahaan. Visi PT Sinar Sakti Kimia yaitu "Berkat rahmat Tuhan Yang Maha Esa serta dilandasi dengan semangat cinta dan syukur, PT Sinar Sakti Kimia berusaha "Bersinar" dengan meningkatkan kualitas, kuantitas, dan kompetitif produk serta akan mengembangkan produkproduk turunannya dengan orientasi peningkatan pelayanan prima dengan penuh kekeluargaan pada para pelanggan, karyawan dan sesama." Visi tersebut menjadi pedoman dalam menjalankan dan mencapai 
tujuan perusahaan. Kegiatan perusahaan seperti kegiatan doa pagi bersama seluruh karyawan juga mencerminkan penerapan kepemimpinan spiritual.

Penerapan kepemimpinan spiritual ikut membentuk budaya organisasi yang mengutamakan cinta dan syukur. Kata-kata cinta dan syukur dituliskan pada semua seragam milik karyawan. Kegiatan wajib selain doa bersama yang dilakukan pada pagi hari juga menyanyikan mars perusahaan. Kegiatan tersebut bertujuan untuk membentuk budaya organisasi yang selaras dengan kepemimpinan spiritual yang dijalankan. Moto "salam, sapa, dan sentuh" dituliskan di dinding agar semua karyawan selalu ingat dan menjadi lebih akrab. Hal tersebut menjadikan perusahaan sebagai tempat yang tertib, bersih, dan sejalan dengan peraturan-peraturan yang pemerintah tetapkan.

Hasil observasi lapangan PT Sinar Sakti Kimia (29 Agustus 2014) diketahui bahwa sebesar 30\% dari total karyawan merupakan karyawan lama yang telah bekerja lebih dari atau sama dengan 5 tahun, sehingga hasil observasi ini dapat dijadikan dasar untuk mengindikasi bahwa tingkat kepuasan kerja karyawan di PT Sinar Sakti Kimia tergolong tinggi.

Berdasarkan latar belakang dan fenomena perusahaan tujuan penelitian ini akan mencoba untuk menggali mengenai hubungan yang terjadi antara kepemimpinan spiritual, budaya organisasi, dan kepuasan kerja karyawan PT Sinar Sakti Kimia.

\section{METODE}

Berdasarkan dari latar belakang dan tujuan penelitian maka dibuat kerangka berpikir yang sesuai dengan penelitian seperti yang digambarkan pada Gambar 1. Kerangka berpikir dibuat untuk memudahkan dalam membuat dan menganalisis hipotesis penelitian.

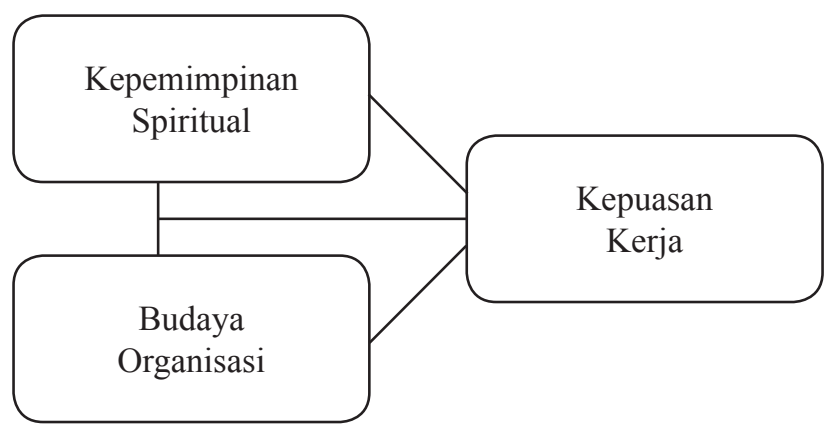

Gambar 1. Kerangka Berpikir
Berdasarkan dari kerangka berpikir seperti yang ditunjukan pada Gambar 1. Maka hipotesis yang akan diuji dalam penelitian ini adalah sebagai berikut:

Hipotesis 1: diduga terdapat pengaruh positif antara kepemimpinan spiritual dengan kepuasan kerja karyawan PT Sinar Sakti Kimia

Hipotesis 2: diduga terdapat pengaruh positif antara budaya organisasi dengan kepuasan kerja karyawan PT Sinar Sakti Kimia

Hipotesis 3: diduga terdapat hubungan positif antara kepemimpinan spiritual dengan budaya organisasi

Hipotesis 4: diduga terdapat pengaruh positif antara kepemimpinan spiritual dan budaya organisasi dengan kepuasan kerja karyawan PT Sinar Sakti Kimia.

\section{Populasi dan Sampel}

Populasi adalah wilayah generalisasi yang terdiri atas objek atau subjek yang mempunyai kualitas dan karakteristik tertentu yang ditetapkan oleh peneliti untuk dipelajari dan kemudian ditarik kesimpulannya (Sugiyono, 2011). Penelitian ini menggunakan populasi yaitu seluruh karyawan PT Sinar Sakti Kimia.

Sampel adalah bagian atau jumlah dan karakteristik yang dimiliki oleh populasi (Sugiyono, 2011). Sampel dalam penelitian ini adalah seluruh karyawan dari PT Sinar Sakti Kimia yang berjumlah 73 orang. Penelitian ini menggunakan non-probability sampling dalam menentukan responden, yaitu sampel yang dipilih secara arbriter (sewenang-wenang) oleh peneliti, atau dengan kata lain, probabilitas masing-masing anggota populasi tidak diketahui (Kuncoro, 2003). Berdasarkan teknik pengambilan non-probability sampling, maka penelitian akan menggunakan teknik sampling jenuh (sensus), yaitu penggunaan seluruh sampel penelitian. Penggunaan teknik sampling jenuh (sensus) berarti menjadikan seluruh karyawan PT Sinar Sakti Kimia yang berjumlah 73 orang sebagai responden dalam penelitian.

\section{Teknik Pengumpulan Data}

Penelitian ini menggunakan metode pengumpulan data dengan menggunakan angket. Angket akan disebarkan kepada responden sesuai dengan teknik pengambilan sampel yang digunakan yaitu sensus. Angket dalam penelitian terdiri dari 3 bagian. 
Pertama adalah angket tentang data diri responden. Angket ini merupakan lembar yang berisikan pertanyaan tentang data diri responden. Pertanyaanpertanyaan yang diajukan dalam kuesioner ini adalah jenis kelamin, umur, pendidikan, lama bekerja, dan divisi yang telah disusun sedemikian rupa sehingga mudah untuk dipahami.

Kedua adalah angket tertutup mengenai pernyataan kepemimpinan spiritual, budaya organisasi, dan kepuasan kerja karyawan. Angket ini berisikan pernyataan-pernyataan yang akan diteliti. Pernyataan diukur dengan menggunakan skala likert. Menurut Sugiyono (2011) yang menyatakan skala likert merupakan metode pengukuran yang digunakan untuk mengukur sikap, pendapat, dan persepsi seseorang atau kelompok orang tentang fenomena sosial. Penggunaan skala likert dimaksudkan untuk mempermudah responden dalam menjawab pernyataan. Skala likert disediakan dalam bentuk lima pilihan jawaban sebagai berikut.

Sangat Tidak Setuju diberi skor 1

Tidak Setuju diberi skor 2

Netral diberi skor 3

Setuju diberi skor 4

Sangat Setuju diberi skor 5

Ketiga adalah angket bersifat terbuka. Angket bersifat terbuka berisikan pertanyaan-pertanyaan yang dapat diisi secara bebas oleh responden. Angket bersifat terbuka akan diajukan tiga pertanyaan yang kemudian dapat dijawab oleh responden secara bebas. Angket bersifat terbuka memiliki tujuan untuk memberikan ruang pada responden untuk memberikan komentar dan saran tentang variabelvariabel yang diteliti. Respon atau jawaban yang diberikan akan dijadikan sebagai pendukung hasil dari angket tertutup yang telah diolah.

Data yang terkumpul kemudian akan diuji kesahihan dan kehandalannya dengan menggunakan taraf signifikansi yang berada dibawah 0,05 akan dikatakan sahih dan jika taraf signifikansi berada di atas 0,05 maka dikatakan tidak sahih. Uji kesahihan dilakukan dengan membandingkan nilai $r$ hitung dengan $r$ tabel. Jika $r$ hitung $>r$ tabel dan bernilai positif, maka pernyataan (indikator) tersebut dikatakan sahih. Uji kehandalan dengan menggunakan uji statistic Cronbach Alpha $(\alpha)$, yaitu suatu variabel dikatakan handal jika memberikan nilai $\alpha \geq 0,60$.

\section{Teknik Analisis Data}

Tabel 2. Kategori interval variabel kepemimpinan spiritual

\begin{tabular}{cl}
\hline Interval & \multicolumn{1}{c}{ Kategori } \\
\hline $1,00-2,00$ & Sangat rendah \\
$2,01-3,00$ & Rendah \\
$3,01-4,01$ & Tinggi \\
$4,01-5,00$ & Sangat tinggi \\
\hline
\end{tabular}

Variabel kepemimpinan spiritual menggunakan indikator visi, harapan/keyakinan, dan kasih alturistik. Hasil dari jawaban responden akan dibagi berdasarkan rata-rata yang didapat sehingga dibagi interval dengan kategori seperti pada Tabel 2.

Variabel budaya organisasi menggunakan indikator innovation and risk taking, people oriented, team oriented, outcome oriented, aggressiveness, dan stability. Hasil dari jawaban responden kemudian akan dibagi berdasarkan rata-rata yang didapat maka akan dibagi interval dengan kategori seperti pada Tabel 3.

Tabel 3. Kategori interval variabel budaya organisasi

\begin{tabular}{cl}
\hline Interval & \multicolumn{1}{c}{ Kategori } \\
\hline $1,00-2,00$ & Sangat lemah \\
$2,01-3,00$ & Lemah \\
$3,01-4,00$ & Kuat \\
$4,01-5,00$ & Sangat kuat \\
\hline
\end{tabular}

Variabel kepuasan kerja menggunakan indikator kepuasan akan gaji, kepuasan akan pekerjaan itu sendiri, kepuasan akan kesempatan promosi, kepuasan akan supervise, dan kepuasan akan rekan kerja. Berdasarkan rata-rata yang didapat maka akan dibagi interval dengan kategori seperti pada Tabel 4.

Tabel 4. Kategori interval variabel kepuasan kerja

\begin{tabular}{cl}
\hline Interval & \multicolumn{1}{c}{ Kategori } \\
\hline $1,00-3,00$ & Tidak puas \\
$3,01-5,00$ & Puas \\
\hline
\end{tabular}


Teknik analisis yang akan digunakan, yaitu pertama tabulasi silang akan dilakukan antara karakteristik responden (jenis kelamin, usia, pendidikan, lama bekerja, dan divisi) dan variabel penelitian (kepemimpinan spiritual, budaya organisasi, dan kepuasan kerja karyawan).

Kedua uji korelasi pearson yang bertujuan untuk menguji hubungan antara dua variabel. Angka dari uji korelasi akan menunjukkan tingkat hubungan antar variabel yang diuji. Nilai dari $r$ hitung dan $r$ tabel dibandingkan dengan taraf kesalahan 5\%. Angka $r$ hitung $>r$ tabel maka terdapat hubungan pada variabel yang diuji.

Ketiga korelasi ganda digunakan untuk menguji apakah terdapat hubungan secara simultan antar variabel penelitian. Pengambilan keputusan jika Sig $>0,05$ maka tidak berpengaruh secara simultan, jika Sig $<0,05$ maka berpengaruh secara simultan.

Keempat yaitu uji chi square yang digunakan untuk mencari hubungan antar variabel. Hasil dari chi square akan digunakan untuk menentukan angka ketergantungan antar variabel.

Kelima yaitu menggunakan metode koefisien kontingensi yang bertujuan untuk menghitung hubungan yang terjadi antar variabel dengan data nominal.

\section{HASIL}

\section{Profil Institusi}

PT Sinar Sakti Kimia adalah perusahaan manufaktur penghasil bahan kimia yang berdiri pada tanggal 3 Juni 1995 dan berlokasi di kota Surakarta dengan alamat Jalan Raya Solo, Sukoharjo Km 7,2 Telukan 57552, Jawa Tengah Indonesia. PT Sinar Sakti Kimia didirikan dan dirintis oleh Thomas Hidayat yang juga merupakan direktur utama. Pertama kali berdiri PT Sinar Sakti Kimia hanya menempati tanah berluaskan $500 \mathrm{~m}^{2}$, namun seiring berjalannya waktu perusahaan mulai memperluas area pabrik dan sekaranag luasnya telah mencapai satu hektar.

PT Sinar Sakti Kimia merupakan satu-satunya pabrik kimia penghasil sodium silicate yang berlokasi di Jawa Tengah. Sodium silicate adalah senyawa yang berasal dari reaksi natrium karbonat $\left(\mathrm{Na}_{2} \mathrm{CO}_{3}\right)$ dengan silikon dioksida $\left(\mathrm{SiO}_{2}\right)$ yang diperoleh dari pasir silika. Hasil produksi dapat digunakan sebagai bahan campuran dalam membuat keramik, sabun, kertas, tekstil, dan kimia. Hasil produksi untuk waterglass dikemas dengan drum-drum maupun menggunakan mobil tangki, sedangkan untuk produk cullet dingin hanya dikemas dengan sak-sak yang berkapasitas $1000 \mathrm{~kg}$ yang kemudian dipasarkan baik didalam dan luar kota. Limbah yang dihasilkan oleh PT Sinar Sakti Kimia juga ramah lingkungan karena sodium silikat sendiri merupakan senyawa kimia yang didapat digunakan sebagai penjernih air.

\section{Uji Kualitas Data}

Hasil uji kesahihan dan kehandalan variabel penelitian bertujuan untuk untuk mengetahui apakah data yang diperoleh itu sahih dan handal. Hasil uji kesahihan variabel penelitian memiliki nilai probabilitas atau signifikansi 0,000 yang lebih kecil daripada nilai $\alpha=0,05$, sehingga dapat dikatakan bahwa setiap indikator dalam variabel penelitian merupakan indikator penelitian yang sahih (Tabel 5.).

Hasil uji kehandalan digunakan untuk menguji konsistensi setiap variabel dalam kuesioner berdasarkan jawaban responden. Pernyataan yang sudah sahih kemudian dapat dinyatakan handal jika koefisien kehandalan tersebut cronbach alpha $\geq 0,6$.

Tabel 5. Hasil uji kehandalan

\begin{tabular}{lcc}
\hline \multicolumn{1}{c}{ Variabel } & Cronbach Alpha & Keterangan \\
\hline Kepemimpinan Spiritual & 0,969 & Handal \\
Budaya Organisasi & 0,960 & Handal \\
Kepuasan Kerja & 0,969 & Handal \\
\hline
\end{tabular}

\section{Analisis Variabel Penelitian}

Rata-rata untuk tiap indikator kepemimpinan spiritual dalam penelitian cenderung netral, yaitu untuk indikator visi rata-rata yang didapat sebesar 3,0658, indikator harapan/keyakinan sebesar 3,0708, dan indikator kasih altruistik sebesar 3,0914. Nilai mean tertinggi yaitu sebesar 3,0914 dengan standar deviasi sebesar 0,96989, sehingga indikator kasih altruistik merupakan indikator kepemimpinan spiritual yang paling tinggi (Tabel 6.). Nilai indikator kasih altruistik adalah menunjukkan bahwa perusahaan cenderung memiliki rasa keutuhan, harmoni, dan kesejahteraan yang dihasilkan melalui kepedulian, perhatian, dan penghargaan untuk diri sendiri dan orang lain. Penelitian yang dilakukan oleh Fani dan Zadeh (2013) juga menunjukkan bahwa indikator kepemimpinan spiritual yaitu kasih altruistik memiliki mean tertinggi. 
Tabel 6. Statistik Deskriptif Kepemimpinan Spiritual

\begin{tabular}{clcc}
\hline No & Indikator & Mean & Standar Deviasi \\
\hline 1 & Visi & 3,0658 & 0,91534 \\
2 & Harapan/Keyakinan & 3,0708 & 0,86110 \\
3 & Kasih Altruistik & 3,0914 & 0,96989 \\
Mean & 3,0760 & 0,89830 \\
\hline
\end{tabular}

Rata-rata untuk tiap indikator budaya organisasi dalam penelitian cenderung netral, yaitu untuk indikator innovation and risk taking rata-rata yang didapat sebesar 3,0137, indikator attention to detail rata-rata yang didapat sebesar 2,9452, indikator outcome oriented rata-rata yang didapat sebesar 2,9932, indikator people oriented rata-rata yang didapat sebesar 3,1096, indikator team oriented rata-rata yang didapat sebesar 3,0548, indikator aggressiveness rata-rata yang didapat sebesar 3,0205, dan indikator stability rata-rata yang didapat 3,0822. Nilai mean tertinggi yaitu sebesar 3,1096 dengan standar deviasi sebesar 0,81329, sehingga indikator people oriented merupakan indikator budaya organisasi yang paling kuat (Tabel 7.). Indikator people oriented menunjukkan bahwa budaya organisasi dalam perusahaan cenderung berorientasi pada orang yaitu bahwa keputusan manajemen mempertimbangkan efek dari hasil pada orang-orang dalam organisasi.

Tabel 7. Statistik Deskriptif Budaya Organisasi

\begin{tabular}{clcc}
\hline No & \multicolumn{1}{c}{ Pernyataan } & Mean & Standar Deviasi \\
\hline 1 & Innovation and risk taking & 3,0137 & 1,08964 \\
2 & Attention to detail & 2,9452 & 0,98094 \\
3 & Outcome oriented & 2,9932 & 0,99824 \\
4 & People oriented & 3,1096 & 0,81329 \\
5 & Team oriented & 3,0548 & 1,03602 \\
6 & Aggressiveness & 3,0205 & 0,88364 \\
7 & Stabillity & 3,0822 & 1,02745 \\
Mean & 3,0316 & 0,88592 \\
\hline
\end{tabular}

Rata-rata untuk tiap indikator dalam penelitian cenderung netral, yaitu untuk indikator kepuasan pada gaji rata-rata yang didapat sebesar 3,1473, indikator kepuasan pada kesempatan promosi sebesar 3,2329, kepuasan pada supervision sebesar 3,3390, indikator kepuasan pada rekan kerja 3,1884, dan indikator kepuasan pada pekerjaan itu sendiri sebesar 3,2637. Nilai mean tertinggi yaitu sebesar 3,3390 dengan standar deviasi sebesar 0,85935 , sehingga indikator kepuasan pada supervision merupakan item kepuasan kerja yang paling tinggi. Rata-rata kepuasan kerja yaitu sebesar 3,2342 yang berarti kepuasan kerja karyawan PT Sinar Sakti Kimia berada di angka netral (Tabel 8.).

Tabel 8. Statistik Deskriptif Kepuasan Kerja

\begin{tabular}{clcc}
\hline No & \multicolumn{1}{c}{ Pernyataan } & Mean & $\begin{array}{c}\text { Standar } \\
\text { Deviasi }\end{array}$ \\
\hline 1 & Kepuasan pada gaji & 3,1473 & 0,89834 \\
2 & Kepuasan pada kesempatan promosi & 3,2329 & 0,81152 \\
3 & Kepuasan pada supervision & 3,3390 & 0,85935 \\
4 & Kepuasan pada rekan kerja & 3,1884 & 0,85063 \\
5 & Kepuasan pada pekerjaan itu sendiri & 3,2637 & 0,85685 \\
Mean & 3,2342 & 0,81193 \\
\hline
\end{tabular}

\section{Analisis Statistik}

Tabulasi silang kepemimpinan spiritual dengan kepuasan kerja dilakukan untuk mengetahui hubungan yang terjadi dan menganalisis hipotesis penelitian. Berikut adalah hasil yang didapat: analisis koefisien kontingensi menunjukkan bahwa nilai koefisien kontingensi adalah sebesar 0,520, dengan nilai approxtimate significant sebesar 0,000 yang lebih kecil daripada $\alpha=0,05$, maka $H o$ ditolak dan $H a$ diterima sehingga menunjukkan bahwa terdapat hubungan antara kepemimpinan spiritual dengan kepuasan kerja. Analisis korelasi menunjukkan nilai koefisien korelasi pearson adalah sebesar 0,524 , sehingga menunjukkan bahwa nilai hubungan kepemimpinan spiritual dengan kepuasan kerja adalah sebesar 0,524, dan dapat dikategorikan sebagai hubungan yang kuat. Analisis chi square menunjukkan bahwa terdapat hubungan signifikan antara kepemimpinan spirital dan kepuasan kerja karena nilai signifikan pada uji chi square sebesar 0,000 lebih kecil dari $\alpha=0,05$. Chi square hitung juga lebih besar dari chi square tabel yaitu sebesar 27,118> 7,815 maka $\mathrm{Ho}$ ditolak dan $\mathrm{Ha}$ diterima. Uji hipotesis atas hasil analisis statistik hubungan kepemimpinan spiritual dengan kepuasan kerja, menunjukkan bahwa uji hipotesis $\left(H_{1}\right)$ diterima dan menyatakan bahwa kepemimpinan spiritual memiliki hubungan dengan kepuasan kerja. Dibuktikan dari angka signifikansi chi square dan koefisien kontingensi yang lebih kecil dari $\alpha=0,05$ (Tabel 9.). 
Tabel 9. Kepemimpinan Spiritual dengan Kepuasan Kerja

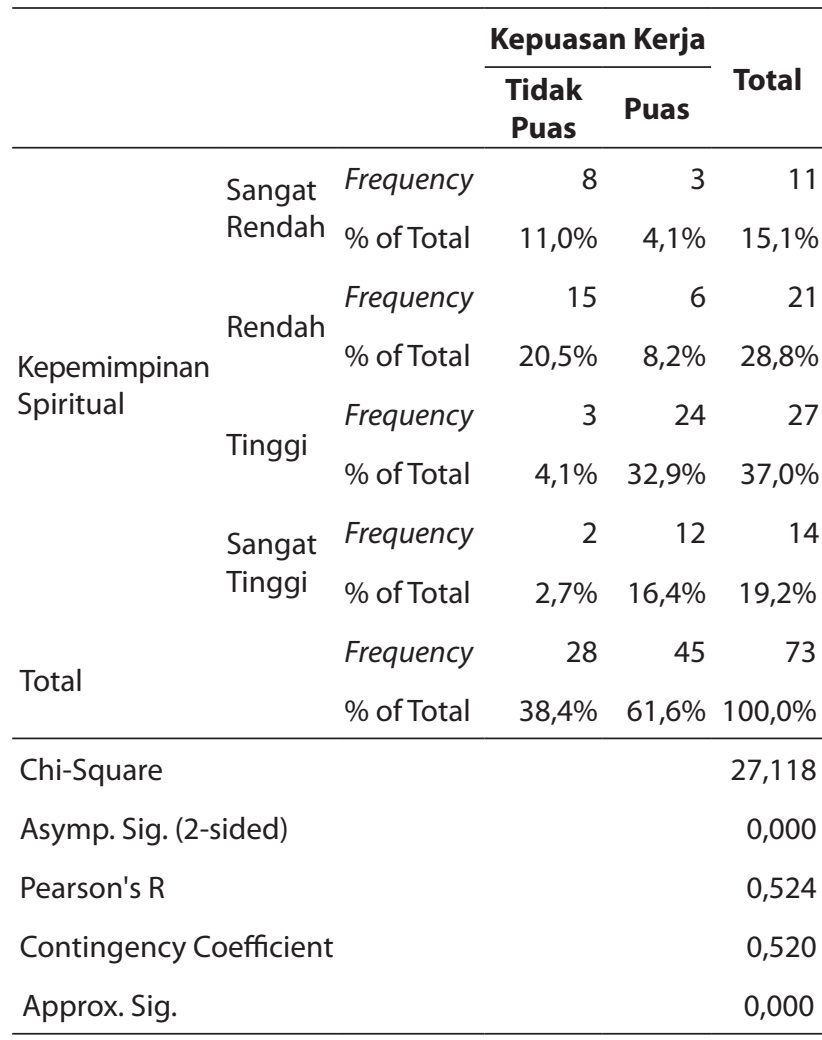

Tabulasi silang budaya organisasi dengan kepuasan kerja dilakukan untuk mengetahui hubungan yang terjadi dan menganalisis hipotesis penelitian. Berikut adalah hasil yang didapat: Analisis koefisien kontingensi menunjukkan bahwa nilai koefisien kontingensi adalah sebesar 0,550, dengan nilai approx.timate significant sebesar 0,000 yang lebih kecil daripada $\alpha=0,05$, maka $H o$ ditolak dan $\mathrm{Ha}$ diterima sehingga menunjukkan bahwa terdapat hubungan antara budaya organisasi dengan kepuasan kerja. Analisis korelasi menunjukkan bahwa nilai koefisien korelasi pearson adalah sebesar 0,524, sehingga menunjukkan bahwa nilai hubungn budaya organisasi dengan kepuasan kerja adalah sebesar 0,524, dan dapat dikategorikan sebagai hubungan yang kuat. Analisis chi square pada Tabel 10. menunjukkan bahwa terdapat hubungan signifikan antara budaya organisasi dan kepuasan kerja karena nilai signifikan pada uji chi square sebesar 0,000 lebih kecil dari $\alpha=0,05$. Chi square hitung juga lebih besar dari chi square tabel yaitu sebesar 31,689 > 7,815 maka $H o$ ditolak dan $\mathrm{Ha}$ diterima. Uji hipotesis atas hasil analisis statistik hubungan budaya organisasi dengan kepuasan kerja, menunjukkan bahwa uji hipotesis $\left(\mathrm{H}_{2}\right)$ diterima dan menyatakan bahwa budaya organisasi memiliki hubungan dengan kepuasan kerja. Dibuktikan dari angka signifikansi chi square dan koefisien kontingensi yang lebih kecil dari $\alpha=0,05$.

Tabel 10. Budaya Organisasi dengan Kepuasan Kerja

\begin{tabular}{|c|c|c|c|c|c|}
\hline & & & \multicolumn{2}{|c|}{ Kepuasan Kerja } & \multirow{2}{*}{ Total } \\
\hline & & & Tidak Puas & Puas & \\
\hline \multirow{8}{*}{$\begin{array}{l}\text { Budaya } \\
\text { Organisasi }\end{array}$} & \multirow{2}{*}{$\begin{array}{l}\text { Sangat } \\
\text { Lemah }\end{array}$} & Frequency & 6 & 3 & 9 \\
\hline & & $\%$ of Total & $8,2 \%$ & $4,1 \%$ & $12,3 \%$ \\
\hline & \multirow{2}{*}{ Lemah } & Frequency & 19 & 7 & 26 \\
\hline & & $\%$ of Total & $26,0 \%$ & $9,6 \%$ & $35,6 \%$ \\
\hline & \multirow{2}{*}{ Kuat } & Frequency & 1 & 24 & 25 \\
\hline & & $\%$ of Total & $1,4 \%$ & $32,9 \%$ & $34,2 \%$ \\
\hline & \multirow{4}{*}{$\begin{array}{l}\text { Sangat } \\
\text { Kuat }\end{array}$} & Frequency & 2 & 11 & 13 \\
\hline & & $\%$ of Total & $2,7 \%$ & $15,1 \%$ & $17,8 \%$ \\
\hline \multirow{2}{*}{ Total } & & Frequency & 28 & 28 & 45 \\
\hline & & $\%$ of Total & $38,4 \%$ & $61,6 \%$ & $100,0 \%$ \\
\hline \multicolumn{3}{|l|}{ Chi-Square } & & & 31,689 \\
\hline \multicolumn{3}{|c|}{ Asymp. Sig. (2-sided) } & & & 0,000 \\
\hline \multicolumn{3}{|l|}{ Pearson's R } & & & 0,524 \\
\hline \multicolumn{3}{|c|}{ Contingency Coefficient } & & & 0,550 \\
\hline \multicolumn{3}{|l|}{ Approx. Sig. } & & & 0,000 \\
\hline
\end{tabular}

Tabulasi silang kepemimpinan spiritual dengan budaya organisasi dilakukan untuk mengetahui hubungan yang terjadi dan menganalisis hipotesis penelitian. Berikut adalah hasil yang didapat: Analisis koefisien kontingensi menunjukkan bahwa nilai koefisien kontingensi adalah sebesar 0,798, dengan nilai approxtimate significant sebesar 0,000 yang lebih kecil daripada $\alpha=0,05$, maka $H o$ ditolak dan $\mathrm{Ha}$ diterima sehingga menunjukkan bahwa terdapat hubungan antara kepemimpinan spiritual dengan budaya organisasi. Analisis korelasi menunjukkan bahwa nilai koefisien korelasi pearson adalah sebesar 0,738 , sehingga menunjukkan bahwa nilai hubungan kepemimpinan spiritual dengan budaya organisasi adalah sebesar 0,738 , dan dapat dikategorikan sebagai hubungan yang kuat. Analisis chi square menunjukkan bahwa terdapat hubungan signifikan antara kepemimpinan spiritual dengan budaya organisasi karena nilai signifikan pada uji chi square sebesar 0,000 lebih kecil dari $\alpha=0,05$. Chi square hitung juga lebih besar dari chi square tabel yaitu sebesar 128,197 > 16,919 maka $\mathrm{Ho}$ ditolak dan $\mathrm{Ha}$ diterima (Tabel 11.). 
Tabel 11. Kepemimpinan Spiritual dengan Budaya Organisasi

\begin{tabular}{|c|c|c|c|c|c|c|c|}
\hline & & & \multicolumn{4}{|c|}{ Budaya Organisasi } & \multirow{2}{*}{ Total } \\
\hline & & & Sangat Lemah & Lemah & Kuat & Sangat Kuat & \\
\hline \multirow{8}{*}{ Kepemimpinan Spiritual } & Sangat Rendah & Frequency & 6 & 3 & 1 & 1 & 11 \\
\hline & & $\%$ of Total & $8,2 \%$ & $4,1 \%$ & $1,4 \%$ & $1,4 \%$ & $15,1 \%$ \\
\hline & Rendah & Frequency & 2 & 19 & 0 & 0 & 21 \\
\hline & & $\%$ of Total & $2,7 \%$ & $26,0 \%$ & $0,0 \%$ & $0,0 \%$ & $28,8 \%$ \\
\hline & Tinggi & Frequency & 0 & 3 & 24 & 0 & 27 \\
\hline & & $\%$ of Total & $0,0 \%$ & $4,1 \%$ & $32,9 \%$ & $0,0 \%$ & $37,0 \%$ \\
\hline & Sangat Tinggi & Frequency & 1 & 1 & 0 & 12 & 14 \\
\hline & & $\%$ of Total & $1,4 \%$ & $1,4 \%$ & $0,0 \%$ & $16,4 \%$ & $19,2 \%$ \\
\hline \multirow{2}{*}{ Total } & & Frequency & 9 & 26 & 25 & 13 & 73 \\
\hline & & $\%$ of Total & $12,3 \%$ & $35,6 \%$ & $34,2 \%$ & $17,8 \%$ & $100,0 \%$ \\
\hline Chi-Square & & & & & & & 128,197 \\
\hline Asymp. Sig. (2-sided) & & & & & & & 0,000 \\
\hline Pearson's R & & & & & & & 0,738 \\
\hline Contingency Coefficient & & & & & & & 0,798 \\
\hline Approx. Sig. & & & & & & & 0,000 \\
\hline
\end{tabular}

Uji hipotesis atas hasil analisis statistik hubungan kepemimpinan spiritual dengan budaya organisasi, menunjukkan bahwa uji hipotesis $\left(H_{3}\right)$ diterima dan menyatakan bahwa kepemimpinan spiritual memiliki hubungan dengan budaya organisasi. Dibuktikan dari angka signifikansi chi square dan koefisien kontingensi yang lebih kecil dari $\alpha=0,05$.

Nilai signifikansi $<0,05$, maka variabel kepemimpinan spiritual dan budaya organisasi memiliki hubungan secara simultan dengan kepuasan kerja. Hasil $R$ menunjukkan bahwa terdapat hubungan positif antara kepemimpinan spiritual dan budaya organisasi dengan kepuasan kerja karyawan PT Sinar Sakti Kimia dengan nilai korelasi sebesar 0,562.

Tabel 12. Analisis Korelasi Berganda

\begin{tabular}{ccc}
\hline Model & R & Sig. \\
\hline 1 & 0,562 & 0,000 \\
\hline
\end{tabular}

Hasil R dari analisis korelasi menunjukkan bahwa uji hipotesis $\left(H_{4}\right)$ diterima yang berarti terdapat hubungan secara simultan antara variabel kepemimpinan spiritual dan budaya organisasi dengan kepuasan kerja karyawan. Variabel kepemimpinan spiritual, budaya organisasi dan kepuasan kerja saling berhubungan positif sehingga ketika budaya organisasi semakin kuat maka akan berdampak positif terhadap kepemimpinan spiritual dan kepuasan kerja. Kepemimpinan spiritual yang semakin tinggi maka budaya organisasi juga akan semakin kuat dan kepuasan kerja akan semakin meningkat.

\section{PEMBAHASAN}

Hasil analisis atas penelitian yang dilakukan di PT Sinar Sakti Kimia menunjukkan bahwa hipotesis terbukti dengan menunjukkan terdapatnya hubungan antara variabel kepemimpinan spiritual, budaya organisasi, dan kepuasan kerja. 
Pengujian hipotesis pertama menunjukkan bahwa terdapat hubungan positif antara kepemimpinan spiritual dengan kepuasan kerja karyawan PT Sinar Sakti Kimia yang dibuktikan dengan angka signifikansi dan angka korelasi, sehingga dengan meningkatnya kepemimpinan spiritual maka akan meningkatkan kepuasan kerja karyawan PT Sinar Sakti Kimia. Fry dan Nisiewicz (2013) mengungkapkan bahwa ketika seseorang berinvestasi pada kehidupan rohaninya maka mereka akan hidup lebih damai dengan diri dan orang lain. Penerapan kepemimpinan spiritual dimaksudkan untuk membawa karyawan lebih dekat kepada sisi rohani sehingga mereka merasakan kepuasan atas pekerjaan. Penelitianpenelitian yang telah dilakukan juga membuktikan dan mendukung bahwa terdapat hubungan positif antara kepemimpinan spiritual dan kepuasan kerja. Penelitian yang dilakukan oleh Abdizadeh et al. (2014) membuktikan bahwa kepemimpinan spiritual memiliki hubungan positif pada kepuasan kerja karyawan. Penelitian yang dilakukan oleh Yusof (2011) juga menggambarkan kerangka kerja yang menunjukkan bahwa kepemimpinan spiritual dan kepuasan kerja memiliki hubungan positif dan signifikan. Penelitian yang dilakukan Bodla et al. (2013) juga membuktikan bahwa indikator kepemimpinan spiritual memiliki hubungan atau pengaruh positif terhadap kepuasan kerja. Penelitian yang dilakukan oleh Masouleh et al. (2013) sejalan dengan penelitian yang dilakukan oleh Asrun et al. (2012) yang mendukung bahwa kepemimpinan spiritual memiliki hubungan positif signifikan terhadap kepuasan kerja karyawan. Hasil uji hipotesis ini membuktikan bahwa dengan kepemimpinan spiritual yang tinggi maka kepuasan kerja juga akan meningkat.

Hasil uji hipotesis kedua menunjukkan bahwa terdapat hubungan positif antara budaya organisasi dengan kepuasan kerja karyawan PT Sinar Sakti Kimia yang dibuktikan dari angka signifikansi dan angka korelasi, sehingga dengan meningkatnya budaya organisasi maka akan meningkatkan kepuasan kerja karyawan PT Sinar Sakti Kimia. Hal ini sesuai dengan yang hasil penelitian yang dilakukan oleh Koesmono (2005) menunjukkan bahwa budaya oganisasi berpengaruh pada kepuasan kerja karyawan. Hasil penelitian yang sama juga ditunjukkan oleh Soedjono (2005) bahwa budaya organisasi berpenaruh signifikan dan positif pada kepuasan kerja karyawan. Davoodalmousavi (2013) juga membuktikan bahwa terdapat hubungan yang signifikan antara budaya organisasi dan kepuasan kerja karyawan. Sesuai dengan teori dan penelitian yang dilakukan oleh Robbins dan Judge (2011) bahwa budaya organisasi sebagai variable intervening memiliki dampak pada kinerja dan kepuasan kerja, semakin kuat budaya maka akan memiliki dampak yang semakin besar. Bentuk budaya organisasi akan berdampak pada kepuasan kerja sehingga perlu untuk menciptakan budaya yang baik dan efektif. Budaya organisasi PT Sinar Sakti Kimia yang paling kuat adalah people oriented yang berarti budaya organisasi perusahaan dalam melakukan keputusan manajemen mempertimbangkan efek dari hasil pada orangorang dalam organisasi. Budaya organisasi yang kuat akan mempengaruhi perilaku anggotanya, sehingga terciptanya budaya organisasi yang positif akan membuat anggota merasakan komitmen yang tinggi terhadap perusahaannya dan juga meningkatkan kepuasan kerja. Kategori budaya organisasi PT Sinar Sakti Kimia berdasarkan teori dari Brown dan Harvey (2006) yaitu berada pada moderate culture karena rata-ratanya sebesar 3,0316.

Hasil uji hipotesis ketiga menunjukkan bahwa terdapat hubungan positif antara kepemimpinan spiritual dengan budaya organisasi PT Sinar Sakti Kimia yang dibuktikan dari angka signifikansi dan angka korelasi, sehingga dapat dikatakan bahwa dengan meningkatnya kepemimpinan spiritual maka akan meningkatkan budaya organisasi PT Sinar Sakti Kimia. Hal ini membuktikan bahwa terdapat hubungan timbal balik antara kepemimpinan spiritual dan budaya organisasi. Penelitian yang dilakukan oleh Fani dan Zadeh (2013) menunjukkan bahwa terdapat hubungan positif dan signifikan antara dimensi kepemimpinan spiritual dengan budaya organisasi. Penelitian yang dilakukan oleh Wibawa et al. (2014) juga membuktikan bahwa budaya organisasi secara positif dan signifikan mempengaruhi kepemimpinan spiritual.Penelitian Karadag(2009)juga membuktikan bahwa kepemimpinan spiritual dan budaya organisasi memiliki hubungan yang positif. Diungkapkan oleh Fry (2003) bahwa kepemimpinan spiritual jugabetugas membangun suatu budaya organisasi berdasarkan cinta altruistik di mana pemimpin dan pengikut sungguh saling perhatian, peduli dan menghargai satu sama lain, sehingga menghasilkan rasa keanggotaan, 
merasa dipahami dan dihargai. Budaya organisasi PT Sinar Sakti Kimia memiliki hubungan yang signifikan dengan kepemimpinan spiritual yang dijalankan oleh perusahaan, sehingga membentuk budaya organisasi berarti juga akan mempengaruhi kepemimpinan spiritual perusahaan begitupula sebaliknya.

Hasil uji hipotesis keempat menunjukkan bahwa terdapat hubungan positif antara kepemimpinan spiritual dan budaya organisasi dengan kepuasan kerja karyawan PT Sinar Sakti Kimia dibuktikan dari nilai $R$, sehingga dapat dikatakan bahwa dengan meningkatnya kepemimpinan spiritual dan budaya organisasi maka akan meningkatkan kepuasan kerja karyawan PT Sinar Sakti Kimia. Hal ini sesuai dengan yang hasil penelitian yang dilakukan oleh Aydin dan Ceylan (2009) yang menunjukkan bahwa kepuasan kerja karyawan memiliki korelasi positif yang signifikan dengan budaya organisasi dan kepemimpinan spiritual.

\section{KESIMPULAN}

Berdasarkan hasil penelitian yang telah ada maka dapat ditarik kesimpulan sebagai berikut: pertama variabel kepemimpinan spiritual memiliki hubungan positif terhadap kepuasan kerja karyawan PT Sinar Sakti Kimia, sehingga menunjukkan bahwa karyawan akan cenderung merasa puas terhadap perusahaan yang memiliki kepemimpinan spiritual yang baik.

Kedua variabel budaya organisasi memiliki hubungan positif terhadap terjadinya kepuasan kerja karyawan PT Sinar Sakti Kimia, sehingga menunjukkan bahwa karyawan akan cenderung merasa puas terhadap perusahaan yang memiliki budaya organisasi yang kuat.

Ketiga variabel kepemimpinan spiritual memiliki hubungan positifterhadap terjadinyabudaya organisasi PT Sinar Sakti Kimia, sehingga menunjukkan bahwa budaya organisasi yang baik dapat dibentuk jika kepemimpinan spiritual baik.

Keempat variabel kepemimpinan spiritual dan budaya organisasi memiliki hubungan positif dengan kepuasan kerja karyawan PT Sinar Sakti Kimia, sehingga menunjukkan bahwa karyawan akan cenderung merasa puas terhadap perusahaan yang memiliki kepemimpinan spiritual dan budaya organisasi yang baik.

Berdasarkan hasil penelitian dan kesimpulan penelitian maka diberikan saran untuk manajemen PT
Sinar Sakti Kimia sebagai berikut: Pertama dengan diterimanya hipotesis pertama maka manajemen PT Sinar Sakti Kimia dalam meningkatkan kepemimpinan spiritual dapat dilakukan dengan mengkomunikaskan visi dan misi secara bertahap sehingga tujuan perusahaan tercapai. Konsistensi dari para pemimpin perusahaan diperlukan karena penerapan dari visi dan misi akan menjadi contoh dan teladan untuk para anggota perusahaan. Secara langsung visi berhubungan dengan kepemimpinan spiritual dan dari hasil analisis, kepemimpinan spiritual juga memiliki hubungan dengan kepuasan kerja, sehingga manajemen perusahaan perlu meninjau lebih lanjut cara pengkomunikasian visi perusahaan agar tercipta kepuasan kerja karyawan.

Kedua, diterimanya hipotesis kedua maka manajemen PT Sinar Sakti Kimia dapat mempertimbangkan penciptaan budaya organisasi yang sesuai dengan identitas perusahaan, karena dari hasil penelitian membuktikan bahwa budaya organisasi memiliki hubungan dengan kepuasan kerja karyawan. Budaya organisasi yang semakin kuat juga akan meningkatkan kepuasan kerja karyawan perusahaan. Peraturan perusahaan merupakan salah satu perwujudan dari budaya organisasi, sehingga perlu diciptakan dan dijalankan secara adil, jelas, dan bijaksana. Manajemen PT Sinar Sakti Kimia perlu mengkomunikasikan kembali peraturan-peraturan yang ada dalam perusahaan sehingga seluruh karyawan merasakan kenyamanan dengan peraturan yang dijalankan.

Ketiga, diterimanya hipotesis ketiga maka manajemen PT Sinar Sakti Kimia dapat mempertimbangkan untuk menerapkan kepemimpinan spiritual dan budaya organisasi secara bersama-sama karena kedua variabel tersebut saling berhubungan. Kegiatan doa bersama, motto cinta dan syukur yang diterapkan oleh Manajemen PT Sinar Sakti Kimia perlu dilakukan secara lebih intensif agar mempengaruhi budaya organisasi, untuk menciptakan perusahaan yang penuh dengan rasa cinta dan syukur.

Keempat, diterimanya hipotesis keempat maka manajemen PT Sinar Sakti Kimia dapat mempertimbangkan untuk menciptakan peningkatan kepuasankerjakaryawandaripenerapankepemimpinan spiritual dan budaya organisasi. Hasil penelitian menunjukkan bahwa kepuasan kerja karyawan dapat ditingkatkan melalui gaji, fasilitas yang diberikan, 
dan promosi. Manajemen PT Sinar Sakti Kimia dapat mengevaluasi kembali secara keseluruhan atas kepemimpinan spiritual yang dijalankan perusahaan dan perwujudan budaya organisasi kepada karyawan sehingga tercipta kepuasan kerja yang semakin meningkat.

\section{DAFTAR PUSTAKA}

Abdizadeh, Mandana, Khiabani, M. M., \& Baroto, Mas Bambang. 2014. Testing the Relationship between Spiritual Leadership and Job Satisfaction in the Iranian Healthcare Industry. European Journal of Scientific Research, 123(2): 203-218.

Asrun et al. 2012. Spiritual Leadership: the Influence Due to Workplace Spirituality, Satisfaction, and Deviant Behavior (Case Study at City Government of Kendari). Journal of Basic and Applied Scientific Research, 2(12): 11978-11983.

Aydin, Bulent \& Adnan Ceylan. 2009. A Research Analysis on Employee Satisfaction in terms of Organizational Culture and Spiritual Leadership. International Journal of Business and Management, 4(3): 159-168.

Bhatti, Komal Khalid \& Qureshi, Tahir Masood. 2007. Impact of Employee Participation on Job Satisfaction, Employee Commitment and Employee Productivity. International Review of Business Research Papers, 3(2): 54-68.

Bodla, M. A., Ali, H. \& Danish, R. Q. 2013. Role of Spiritual Leaders in Enhancing Employee's Performance, Journal of Basic and Applied Scientific Research, 3(3):117-122.

Brown, Donald R. \& Harvey, Donald F. 2011. An ExperientialApproachto OrganizationDevelopment ( $8^{\text {th }}$ edition). New Jersey: Pearson Prentice Hall.

Davoodalmousavi, S. M. 2013. The Correlation Between Organizational Culture and Job Satisfaction of Employees in Biotechnology Production Companies. European Journal of Experimental Biology, 3(5): 389-399.

Fani, Majid \& Zadeh, Mehrdad Hossien. 2013. Inquiry of the Relationship Between Organizational Culture and Spiritual Leadership in Governmental Organization in "Mazandaran". Journal of Applied Science and Agriculture, 8(5): 737-743.

Fry, Louis W. 2003. Toward a Theory of Spiritual Leadership. The Leadership Quarterly, 14: 693-727.
Fry, Louis W., \& Nisiewicz, M. 2013. Maximizing the Triple Bottom Line through Spiritual Leadership. Stanford: Stanford University Press.

Karadag, Engin. 2009. Spiritual Leadership and Organizational Culture: A Study of Structural Equation Modeling. Educational Sciences: Theory \& Practice, 9(3): 1391-1405.

Koesmono,H.Teman. 2005.Pengaruh Budaya Organisasi terhadap Motivasi dan Kepuasan Kerja serta Kinerja Karyawan pada Sub Sektor Industri Pengolahan Kayu Skala Menengah di Jawa Timur. Jurnal Manajemen dan Kewirausahaan, 7(2): 162-179.

Kuncoro, Mudrajad. 2003. Metode Riset untuk Bisnis dan Ekonomi. Jakarta: Erlangga.

Lunenburg, Fred C. 2011. Understanding Organizational Culture: A Key Leadership Asset. National Forum of Educational Administration and Supervision Journal, 29(4): 1-12.

Masouleh, Saeid Askari et al. 2013. Studying the Relationship Between Spiritual Leadership and Job Satisfaction. Elixir Human Resource Management, 56: 13476-13480.

Muslich, Ahmad. 2014. Nilai Spiritual dalam Bisnis. Kompasiana. [Online]Tersedia:www.kompasiana. $\mathrm{com} / w w w . i d a m a n s b y . c o m / n i l a i-s p i r i t u a l-d a l a m-$ bisnis_55287be76ea834ea5e8b4567[7 September 2014]

Robbins, Stephen P. \& Judge, Timothy A. 2011. Organizational behavior (14 ${ }^{\text {th }}$ edition). New Jersey: Pearson Education.

Satyawati, Ni Made Ria \& Suartana, I Wayan. 2014. Pengaruh Gaya Kepemimpinan dan Budaya Organisasi terhadap Kepuasan Kerja yang Berdampak pada Kinerja Keuangan. E-Jurnal Akuntansi Universitas Udayana, 6(1): 17-32.

Soedjono. 2005. Pengaruh Budaya Organisasi terhadap Kinerja Organisasi dan Kepuasan Kerja Karyawan pada Terminal Penumpang Umum di Surabaya. Jurnal Manajemen dan Kewirausahaan, 7(1): 22-47.

Srinivasan, Leela, Sam Gager \& Maria Ignatova. 2014. Talent Trends 2014: What's on the Minds of the Professional Workforce [Online]. Tersedia: http://talent.linkedin.com [7 September 2014]

Sugiyono, 2011. Metode Penelitian Kuantitatif, Kualitatif, dan R\&D. Bandung: Alfabeta. 
Wibawa, I Made Artha et al. 2014. The Role of Organizational Culture on Spiritual Leadership, Human Capital, and Employee Loyalty. European Journal of Business and Management, 6(21): 144-153.
Yusof, Juhaizi Mohd. 2011. A Multidimensional Approach in the Relationship Between Spiritual Leadership and Job Satisfaction: A Conceptual Framework. Proceedings of 2nd International Conference on Business and Economic Research, 2461-2479. 